\title{
CAMA
}

Centre for Applied Macroeconomic Analysis

\section{Can Italy Grow Out of Its NPL Overhang? A Panel Threshold Analysis}

\section{CAMA Working Paper 28/2017 April 2017}

\section{Kamiar Mohaddes}

Faculty of Economics and Girton College, University of Cambridge and Centre for Applied Macroeconomic Analysis, ANU

\section{Mehdi Raissi}

International Monetary Fund

\section{Anke Weber}

International Monetary Fund

\begin{abstract}
This paper examines whether a tipping point exists for real GDP growth in Italy above which the ratio of non-performing loans (NPLs) to total loans falls significantly. Estimating a heterogeneous dynamic panel-threshold model with data on 17 Italian regions over the period 1997-2014, we provide evidence for the presence of growththreshold effects on the NPL ratio in Italy. More specifically, we find that real GDP growth above 1.2 percent, if sustained for a number of years, is associated with a significant decline in the NPLs ratio. Achieving such growth rates requires decisively tackling long standing structural rigidities and improving the quality of fiscal policy. Given the modest potential growth outlook, however, under which banks are likely to struggle to grow out of their NPL overhang, further policy measures are needed to put the NPL ratio on a firm downward path over the medium term.
\end{abstract}




\section{Keywords}

Italy, non-performing loans, real output growth, panel tests of threshold effects

\section{JEL Classification}

C23, E44, G33

Address for correspondence:

(E) cama.admin@anu.edu.au

ISSN 2206-0332

The Centre for Applied Macroeconomic Analysis in the Crawford School of Public Policy has been established to build strong links between professional macroeconomists. It provides a forum for quality macroeconomic research and discussion of policy issues between academia, government and the private sector.

The Crawford School of Public Policy is the Australian National University's public policy school, serving and influencing Australia, Asia and the Pacific through advanced policy research, graduate and executive education, and policy impact. 


\title{
Can Italy Grow Out of Its NPL Overhang? A Panel Threshold Analysis*
}

\author{
Kamiar Mohaddes ${ }^{\text {ab }}$, Mehdi Raissi ${ }^{\mathrm{c} \dagger}$, and Anke Weber ${ }^{\mathrm{c}}$ \\ ${ }^{a}$ Faculty of Economics and Girton College, University of Cambridge, UK \\ b Centre for Applied Macroeconomic Analysis, ANU, Australia \\ ${ }^{\mathrm{c}}$ International Monetary Fund, Washington DC, USA
}

March 1, 2017

\begin{abstract}
This paper examines whether a tipping point exists for real GDP growth in Italy above which the ratio of non-performing loans (NPLs) to total loans falls significantly. Estimating a heterogeneous dynamic panel-threshold model with data on 17 Italian regions over the period 1997-2014, we provide evidence for the presence of growththreshold effects on the NPL ratio in Italy. More specifically, we find that real GDP growth above 1.2 percent, if sustained for a number of years, is associated with a significant decline in the NPLs ratio. Achieving such growth rates requires decisively tackling long-standing structural rigidities and improving the quality of fiscal policy. Given the modest potential growth outlook, however, under which banks are likely to struggle to grow out of their NPL overhang, further policy measures are needed to put the NPL ratio on a firm downward path over the medium term.
\end{abstract}

JEL Classifications: C23, E44, G33.

Keywords: Italy, non-performing loans, real output growth, panel tests of threshold effects.

${ }^{*}$ We are grateful to Athanasios V. Arvanitis, Antonio Bassanetti, Oya Celasun, Carlo Cottarelli, Rishi Goyal, Bertrand Gruss, Dermot Monaghan, Maria Soledad Martinez Peria, and Rachel N. van Elkan as well as colleagues from the Bank of Italy and the Ministry of Economy and Finance for helpful comments and suggestions. The views expressed in this paper are those of the authors and do not necessarily represent those of the International Monetary Fund or IMF policy.

${ }^{\dagger}$ Corresponding author. Email address: mraissi@imf.org. 


\section{Introduction}

The ratio of non-performing loans (NPLs) to total loans in Italy has reached very high levels (see Figure 1) post global financial crisis. Total NPLs appear to have broadly stabilized at about $€ 356$ billion at end-June 2016 (about 18 percent of total loans; 20 percent of GDP; and one-third of the Euro Area total), and, as a ratio of total assets, they were mostly concentrated in the south of the country (see Figure 2). ${ }^{1}$ High NPLs are a drag on bank profitability and may also adversely affect economic activity in various ways. First, a bank experiencing high NPLs will likely focus on internal consolidation and improving asset quality rather than providing new credit to the private sector. Second, high NPLs require greater loan loss provisions, which reduce the available resources for lending. ${ }^{2}$ Third, an NPL overhang can result in a misallocation of resources - diverting funds away from more productive parts of the economy, thereby hampering a country's long-term growth prospects; see Peek and Rosengren (2005) and Caballero et al. (2008) who explore the phenomenon of zombie lending and evergreening in Japan. ${ }^{3}$

In addition to active policy measures to tackle NPLs, cyclical factors can play a role in reducing NPLs. Faster economic growth is expected to lead not only to an expansion in total credit (the denominator of NPL ratio) but also in a stabilization or reduction in stock of NPLs (the numerator) through (i) a reduction in the new flow of NPLs as firms' probability of default falls; (ii) an improvement in prospects of firms whose loans may have become non performing, resulting in previous NPLs becoming performing again; (iii) an increase in the disposal of NPLs as recovery values improve; and (iv) an increase in bank profitability, leading to higher retained earnings, higher provisions and greater write offs (see Jobst and Weber 2016). ${ }^{4}$

\footnotetext{
${ }^{1}$ Net of provisions, current NPLs amount to about 191 billion (10.4 percent of total loans); out of these, 88 billion (4.8 percent of loans) are represented by bad loans - i.e. exposures to insolvent debtors; the remaining 103 billion relate to situations in which repayments may still resume.

${ }^{2}$ See also Dörr et al. 2017 who examine the implications for firm productivity of adverse shocks to bank lending in Italy. They finnd that a negative shock to bank credit supply reduces firms' loan growth, investment, capital-to-labor ratio, and productivity.

${ }^{3}$ The empirical literature points to some feedback effects from NPLs to growth. For Italy, Filosa (2007) concludes that deterioration (improvement) in the quality of loans weakens (reinforces) real economic activity and inflation in Italy. Klein (2013) shows that an increase in NPLs has a significant negative impact on credit, real GDP growth, unemployment, and inflation in emerging Europe. Nkusu (2011) estimates the reaction of an economy to a sudden increase in the NPL ratio in a sample of 26 developed countries and finds a strong negative impact that persists for four years after the initial shock. Using a newly constructed dataset on NPL reduction episodes, Balgova et al. (2016) illustrate that a reduction in NPL ratios leads to faster GDP growth, higher credit growth and investment, and better labor market outcomes.

${ }^{4}$ The modest economic recovery in Italy since 2014 has resulted in a gradual improvement in the quality of credit: the flow of new NPLs has decreased to the lowest levels since 2008 and the total stock of NPLs has broadly stabilized since the end of 2015 .
} 
Figure 1: Evolution of the NPL Ratio Over Time

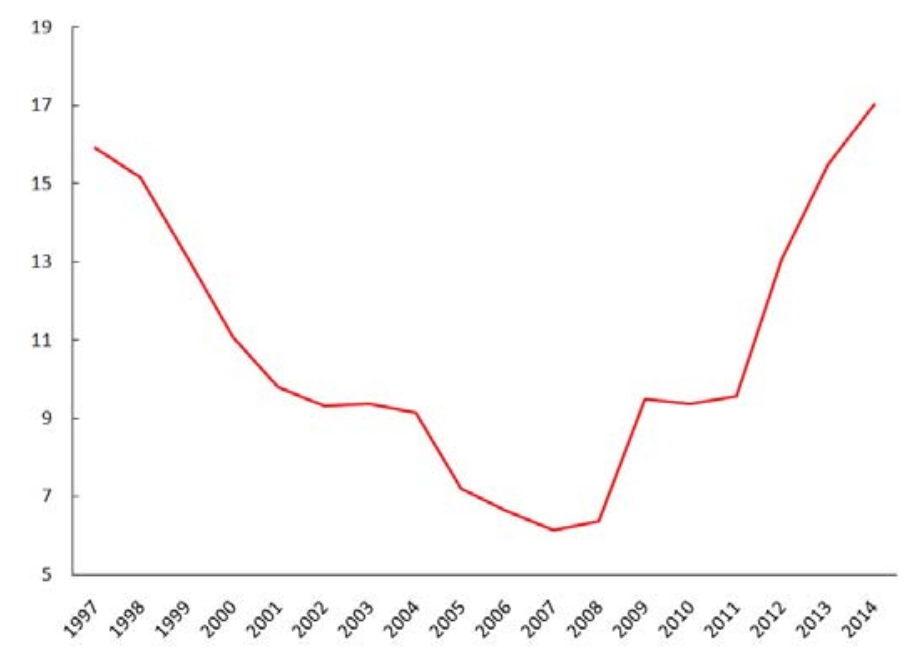

Source: Authors' construction based on Bank of Italy data.

Figure 2: Geographical Distribution of NPL Ratios (Averages over 1997-2014)

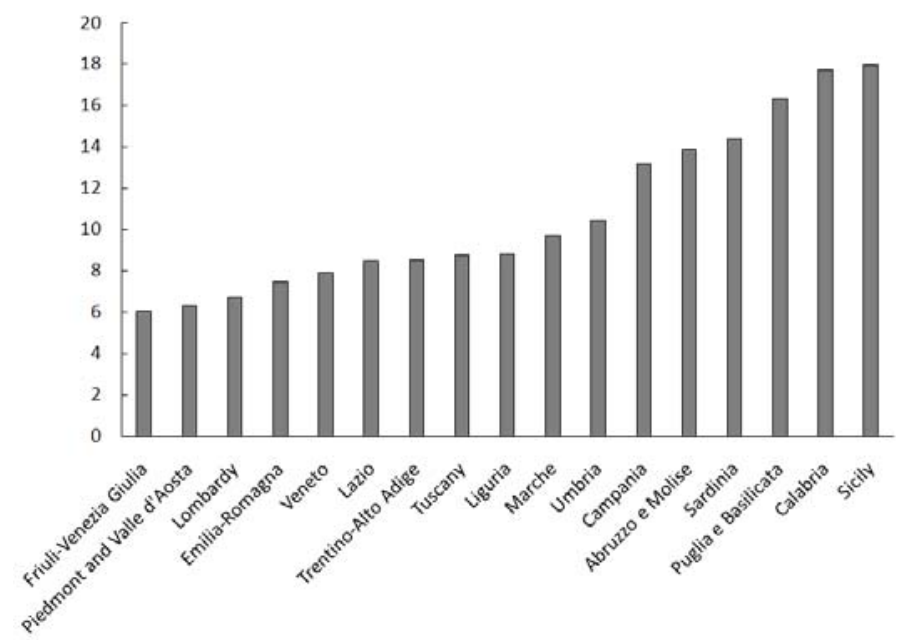

Source: Authors' construction based on Bank of Italy data. 
Empirical evidence indeed suggests that economic activity is one of the main drivers of NPL ratios. Beck et al. (2013) find that for a dynamic panel of 75 advanced and emerging economies, real GDP growth is the most important determinant of asset quality. Nonetheless, other factors such as exchange rate and interest rate movements may also play a role. These findings are broadly in line with other cross-country analyses; see, for instance, Espinoza and Prasad (2010), Nkusu (2011), Glen and Mondragón-Vélez (2011), and Klein (2013). With regard to Italy-specific studies, using a dynamic panel-data analysis covering the 62 largest Italian banks, Garrido et al. (2016) show that while economic growth has been the most important determinant of the NPL buildup following the crisis, this was exacerbated by bank specific factors. Quagliariello (2007) concludes that Italian banks' riskiness and profitability are affected by the evolution of the business cycle. Using Italian credit registry data, Bofondi and Ropele (2011) find that the quality of lending to households and firms can be explained by a small number of macroeconomic variables mainly related to the general state of the economy, the cost of borrowing, and the burden of debt. Finally, Notarpietro and Rodano (2016) argue that the slowdown in GDP growth following the global financial crisis and the European sovereign debt crisis is a major contributor to the rise in bad debts in Italy.

Motivated by the above cross-country experience, which highlights the importance of fast growth for reducing NPLs, this paper asks: Can Italy grow out of its NPL overhang? We contribute to the literature by investigating whether there is a non-monotonic relationship between real GDP growth and the NPL ratio in Italy while accounting for potential feedback effects from the NPL ratio to real GDP growth. In other words, we investigate whether there exists a tipping point for real GDP growth in Italy beyond which the NPL ratio falls significantly (i.e., by about 5-10 percent per year). To this end, we specify a heterogeneous dynamic panel-threshold model and provide formal statistical tests of growth-threshold effects on NPL ratios in a sample of 17 Italian regions over the period 1997-2014.

There are a number of advantages to our within-country analysis relying on Italian regionlevel GDP growth and NPL ratios data, as opposed to investigating the non-linear relationship between the NPL ratio and growth by conducting cross-country or time-series analysis for Italy. For instance, estimating the growth threshold on NPL ratios in a cross-country framework runs the risk of being distorted owing to cross-country heterogeneity and varying definitions of NPLs. Moreover, utilizing within country data allows for a more accurate/efficient inference of model parameters than from time-series regressions using all-Italy data or from cross-country panel data models. Note also that our estimation strategy takes into account dynamics, regional heterogeneity, and feedback effects between NPL ratios and growth. Acknowledging that cyclical developments are an important driver of NPL ratios in Italy, we distinguish between the short-term and long-term effects of faster growth on NPL 
ratios, and focus on the latter.

We find a statistically significant growth-threshold effect on the NPL ratio in Italy at about 1.2 percent, once we account for cross-region heterogeneities, simultaneous determination of the NPL ratio and growth, and dynamics. Moreover, we find that there is a significant and robust negative long-run association between economic growth and NPL ratios. Quantitatively, a one percentage points faster growth than the baseline in Italy, if persistent, would reduce the NPL ratio by about 6.5 to 9.5 percent per year (i.e. halving the NPL ratio in $3-6$ years).

Given Italy's moderate growth outlook, banks could thus struggle to grow out of their NPL overhang. Italy has experienced historically weak economic growth (and negative productivity growth) predating the global financial crisis (Figure 3). It is, therefore, important for Italy to improve its growth prospects compared to the currently moderate outlook - see Figure 4-(with real GDP growth projected by a number of analysts including IMF staff, European Commission, OECD, some investment banks and think tanks to remain close to 1 percent over the next few years) by fully implementing the reform efforts pursued in recent years and scaling them up, lowering Italy's high levels of public debt, and ensuring a pro-growth mix of spending and tax measures.

Figure 3: Average Real GDP and TFP Growth (1997-2014)

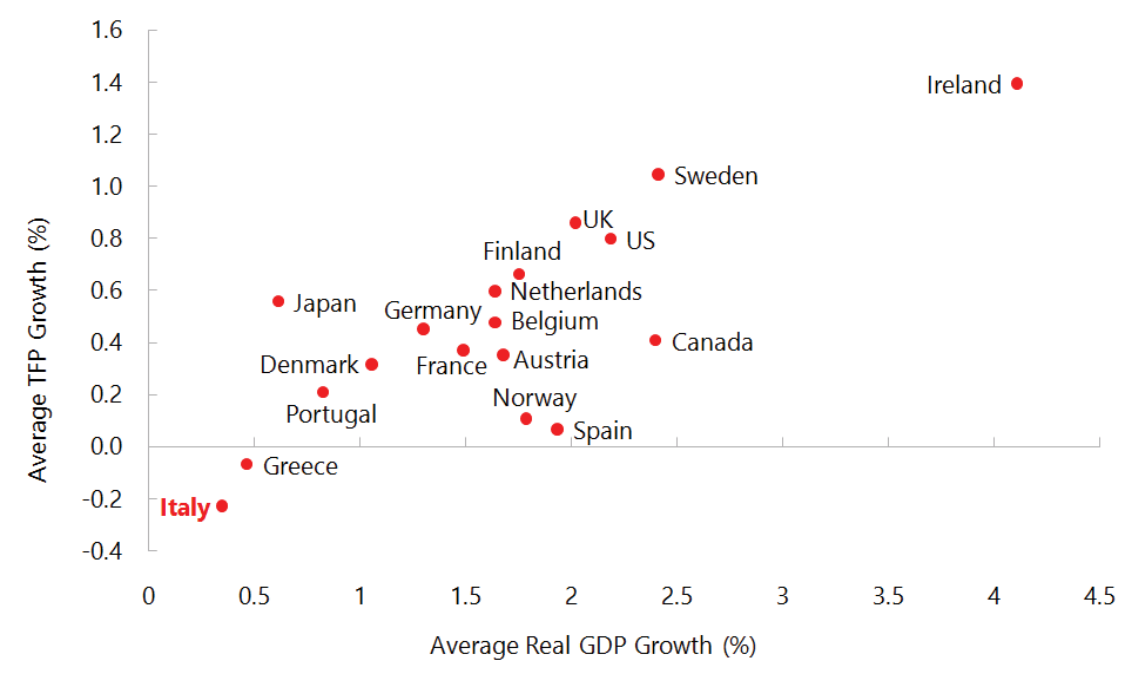

Source: The annual macro-economic database of the European Commission's Directorate General for Economic and Financial Affairs (AMECO).

This also means that active NPL resolution measures are needed to bring NPL ratios on a firm downward trajectory over the medium term. The Italian authorities have already 
Figure 4: Real GDP Growth (1997-2021)

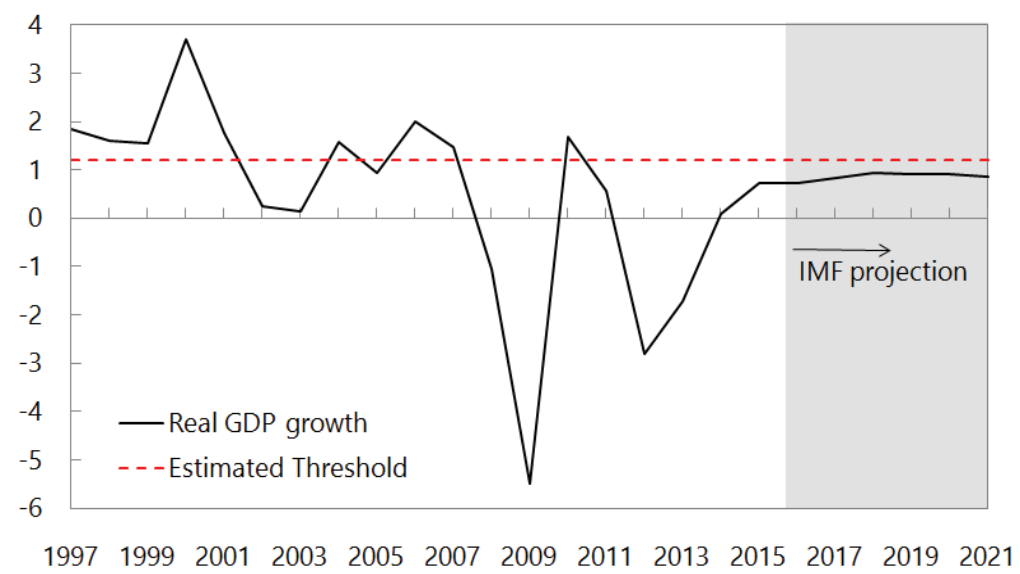

Source: Authors' estimates and IMF projections.

introduced several measures to deal with the NPL problem. These include steps to improve the insolvency system, foster consolidation within the highly fragmented banking sector, and facilitate securitization and sale of NPLs. However, the insolvency reforms, once fully implemented, are expected to yield benefits only gradually over time. Thus, additional measures are needed to deal with the existing high stock of NPLs, including more intensive use of out-of-court debt restructuring mechanisms; strengthened supervision; and a systematic assessment of asset quality for banks not already subject to the ECB comprehensive assessment, with follow-up actions in line with regulatory requirements; for more details, see Garrido et al. (2016). Should the need arise, effective use of the framework for the prompt resolution of banks is also important and concerns related to the bail-in of retail investors should be dealt with appropriately (International Monetary Fund 2016).

The remainder of the paper is organized as follows. Section 2 presents our panel threshold model. Section 3 reports the findings on growth-threshold effects and the long-run relationship between economic growth and the NPL ratio. Section 4 offers some concluding remarks. 


\section{A panel threshold NPL ratio-growth model}

We begin our econometric analysis with the following specification for the change in NPL ratio $\left(\Delta d_{i t}\right)$ :

$$
\begin{aligned}
& \Delta d_{i t}=\alpha_{i, d}+\varphi I\left(\Delta y_{i t}>\tau\right)+\delta \Delta d_{i, t-1}+\eta \Delta y_{i, t-1}+e_{i t}, \\
& \text { for } i=1,2, \ldots, N, \text { and } t=1,2, \ldots, T,
\end{aligned}
$$

and combine it with an equation for real GDP growth, $\Delta y_{i t}$

$$
\Delta y_{i t}=\alpha_{i, y}+\varkappa \Delta y_{i, t-1}+\psi \Delta d_{i, t-1}+\varepsilon_{i t},
$$

Both specifications include fixed effects, $\alpha_{i, d}$ and $\alpha_{i, y}$, but to simplify the exposition, we initially assume homogeneous slopes. Equation (2) allows for feedbacks from lagged NPLratio growth $(\psi \neq 0)$ to real GDP growth. It is important to note that even if $\tau$ was known, estimates of $\varphi$ based on (1), would be subject to a substantial simultaneity bias when $\varepsilon_{i t}$ is correlated with $e_{i t}$, regardless of whether lagged variables are present in (1) and/or (2). To deal with this bias, we model the correlation between the two innovations and derive a reduced form equation, which allows us to identify the threshold effect in the NPL-ratio equation, given that the threshold variable is excluded from the growth equation (our identification condition). ${ }^{5}$ To this end, assuming a linear dependence between the innovations, we have

$$
e_{i t}=\kappa_{i} \varepsilon_{i t}+u_{i t}
$$

where $u_{i t}=e_{i t}-E\left(e_{i t} \mid \varepsilon_{i t}\right)$, and by construction $u_{i t}$ and $\varepsilon_{i t}$ are uncorrelated. The coefficient $\kappa_{i}$ measures the degree of simultaneity between NPL ratio and growth innovations for region $i$. Substituting (3) in (1) and then substituting (2) for $\varepsilon_{i t}$, we obtain the following "reduced form" panel threshold-ARDL specification for $\Delta d_{i t}$ :

$$
\Delta d_{i t}=c_{i}+\varphi I\left(\Delta y_{i t}>\tau\right)+\lambda_{i} \Delta d_{i, t-1}+\beta_{i 0} \Delta y_{i t}+\beta_{i 1} \Delta y_{i, t-1}+u_{i t},
$$

where $c_{i}=\alpha_{i, d}-\kappa_{i} \alpha_{i, y}, \lambda_{i}=\delta-\kappa_{i} \psi, \beta_{i 0}=\kappa_{i}$, and $\beta_{i 1}=\eta-\kappa_{i} \varkappa$. Conditional on $\left(\Delta d_{i, t-1}, \Delta y_{i t}, \Delta y_{i, t-1}\right)$ and under our identification assumption, $u_{i t}$ and $I\left[\Delta y_{i t}>\tau\right]$ are uncorrelated and, hence, for a given value of $\tau, \varphi$ can be consistently estimated after the fixed effects and the heterogeneous dynamics are filtered out. The threshold coefficient, $\tau$, can then be estimated by a grid search procedure, see Chudik et al. (2017) for details. Since the

\footnotetext{
${ }^{5}$ Nonetheless, we do not rule out the possibility of indirect threshold effects through the feedback variable, $\Delta d_{i, t-1}$.
} 
focus of the analysis is on $\varphi$, assumed to be homogeneous, (4) can be estimated treating the other coefficients, $c_{i}, \lambda_{i}, \beta_{i 0}, \beta_{i 1}$, as heterogeneous. ${ }^{6}$

\subsection{Panel tests of threshold effects}

Testing the hypothesis $\varphi=0$ requires non-standard test statistics because under $\varphi=0$, the threshold parameter $\tau$ disappears. Chudik et al. (2017) develop such tests in the context of heterogenous dynamic panel data models. ${ }^{7}$ Using vector notations and replacing $\varphi I\left[\Delta y_{i t}>\tau\right]$ in (1) with $\varphi^{\prime} \mathbf{f}\left(\Delta y_{i t}, \tau\right),{ }^{8}$ equation (4) for $t=1,2, \ldots, T$ can be written compactly as

$$
\Delta \mathbf{d}_{i}=\mathbf{Q}_{i} \boldsymbol{\theta}_{i}+\varphi^{\prime} \mathbf{F}_{i}(\tau)+\mathbf{u}_{i}, \text { for } i=1,2, \ldots, N,
$$

where $\Delta \mathbf{d}_{i}$ is a $T \times 1$ vector of observations on $\Delta d_{i t}, \mathbf{Q}_{i}$ is a $T \times h$ observation matrix of regressors $\mathbf{q}_{i t}=\left(1, \Delta d_{i, t-1}, \Delta y_{i t}, \Delta y_{i, t-1}\right)^{\prime}, h=4$, and $\mathbf{F}_{i}(\tau)$ is a $T \times r$ matrix of observations on the threshold variables in $\mathbf{f}\left(\Delta y_{i t}, \tau\right)$. The filtered pooled estimator of $\boldsymbol{\varphi}$ for a given value of $\tau$ is given by

$$
\hat{\boldsymbol{\varphi}}(\tau)=\left[\sum_{i=1}^{N} \mathbf{F}_{i}^{\prime}(\tau) \mathbf{M}_{i} \mathbf{F}_{i}(\tau)\right]^{-1} \sum_{i=1}^{N} \mathbf{F}_{i}^{\prime}(\tau) \mathbf{M}_{i} \Delta \mathbf{d}_{i},
$$

where $\mathbf{M}_{i}=\mathbf{I}_{T}-\mathbf{Q}_{i}\left(\mathbf{Q}_{i}^{\prime} \mathbf{Q}_{i}\right)^{-1} \mathbf{Q}_{i}$, and $\mathbf{Q}_{i}$ covers the set of regressors (filtering variables) in specifications (1) and (2), from which the empirical panel threshold-ARDL model (4) is derived. The SupF test statistic for testing the null hypothesis $\boldsymbol{\varphi}=\mathbf{0}$ is given by

$$
S u p F=\sup _{\tau \in \mathcal{H}}\left[F_{N T}(\tau)\right]
$$

where $\mathcal{H}$ represents the admissible set of values for $\tau$ and

$$
F_{N T}(\tau)=\frac{\left(R S S_{r}-R S S_{u}\right) / r}{R S S_{u} /(n-s)}
$$

in which $R S S_{u}$ is the residual sum of squares of an unrestricted model (5), $R S S_{r}$ is the residual sum of squares of the restricted model under the null $\varphi=0, n$ is the number of

\footnotetext{
${ }^{6}$ Owing to the intrinsic regional heterogeneities in Italy, the growth thresholds are most-likely region specific. Relaxing the homogeneity assumption, whilst possible in a number of dimensions, is difficult when it comes to the estimation of region-specific thresholds, because due to the non-linearity of the relationships involved, identification and estimation of region-specific thresholds require much larger time series data than are currently available. Moreover, the methodology treats the threshold variable as being time-invariant, while it might have decreased with underlying improvements in insolvency regime over time.

${ }^{7}$ For a recent empirical application of the panel test of threshold effects see Mohaddes and Raissi (2016).

${ }^{8}$ Where $\mathbf{f}\left(\Delta y_{i t}, \tau\right)$ is a vector of $r$ threshold variables and $\varphi$ is the $r \times 1$ vector of corresponding threshold coefficients.
} 
available observations $(n=N T)$, and $s$ is the total number of estimated coefficients in the unrestricted model $(s=N h+r)$. Similarly, we define AveF test statistics as

$$
\text { AveF }=\frac{1}{\# \mathcal{H}} \sum_{\tau \in \mathcal{H}} F_{N T}(\tau)
$$

where $\# \mathcal{H}$ denotes the number of elements of $\mathcal{H}$. The asymptotic distributions of the SupF and AveF test statistics are non-standard, but can be easily simulated. When only one threshold variable is considered $(r=1)$, as is the case in our empirical application, we use the square root of $F_{N T}(\tau)$ in (6) and (7) to obtain the Sup $\mathcal{T}$ and Ave $\mathcal{T}$ test statistics, respectively.

\section{Empirical findings}

We argue that the relationship between economic growth and the NPL ratio is non-monotonici.e., a real GDP growth above a certain threshold is needed to reduce the NPL ratio significantly. To support this argument, we construct regional NPL ratios based on supervisory returns data from the Bank of Italy and obtain regional real GDP data from Italy's National Institute for Statistics (Istat), ${ }^{9}$ and then provide a formal statistical analysis of growth-threshold effects on NPL ratios, using a panel of 17 Italian regions over the period 1997-2014. We allow for region-specific heterogeneity in dynamics, error variances, and cross-region correlations, but assume homogeneous threshold parameters. Furthermore, we examine the long-term effects of economic growth on NPL ratios using both ARDL and DL specifications discussed in Chudik et al. (2016).

\subsection{Tests of the growth-threshold effects}

We begin with the following baseline autoregressive distributed lag (ARDL) specification, which extends (4) to $p$ lags,

$$
\Delta d_{i t}=c_{i}+\varphi I\left(\Delta y_{i t}>\tau\right)+\sum_{\ell=1}^{p} \lambda_{i} \Delta d_{i, t-\ell}+\sum_{\ell=0}^{p} \beta_{i \ell} \Delta y_{i, t-\ell}+v_{i t},
$$

\footnotetext{
${ }^{9}$ We use end-of-year data on NPL ratios by region. From 1997-2007, we use supervisory returns data compiled by the Bank of Italy on the non-performing/total loans ratio (percentage) for the different regions. NPLs comprise overdue, substandard, restructured and impaired loans. From 2008-2014, we compile our own NPL ratio adding up loans across those four NPL categories and dividing them by total loans (total maturity). We have data on 17 regions, as opposed to 20, as some regions are grouped together in the Bank of Italy's statistical database after 2007.
} 
and, following Chudik et al. (2016), we also consider the alternative approach of estimating the long-run effects using the distributed lag (DL) counterpart of (8), given by

$$
\Delta d_{i t}=c_{i}+\theta I\left(\Delta y_{i t}>\tau\right)+\phi_{i} \Delta y_{i t}+\sum_{\ell=0}^{p} \alpha_{i \ell} \Delta^{2} y_{i, t-\ell}+v_{i t}
$$

The threshold variable $I\left(\Delta y_{i t}>\tau\right)$ takes the value of 1 if real GDP growth is above $\tau$ and zero otherwise. As before $y_{i t}$ is the log of real GDP and $d_{i t}$ is the log of NPL ratio. As explained in Chudik et al. (2016), sufficiently long lags are necessary for the consistency of the ARDL estimates, whereas specifying longer lags than necessary can lead to estimates with poor small sample properties. The DL method, on the other hand, is more generally applicable and only requires that a truncation lag order is selected. We use the same lag order, $p$, for all variables/regions but consider different values of $p$, with $p_{\max }=2$, to investigate the sensitivity of the results to the choice of the lag order. Note that the maximum lag order of 2 should be sufficient to fully account for the short-run dynamics given that we are working with growth rates, see Chudik et al. (2017) for details.

Table 1: Tests of real GDP growth-threshold effects on changes in NPL ratios

\begin{tabular}{|c|c|c|c|c|c|}
\hline \multirow[b]{2}{*}{ lags: } & \multicolumn{2}{|c|}{ ARDL } & \multicolumn{3}{|c|}{ DL } \\
\hline & $(1,1)$ & $(2,2)$ & $\mathrm{p}=0$ & $\mathrm{p}=1$ & $\mathrm{p}=2$ \\
\hline \multicolumn{6}{|c|}{ Regressions with threshold variable $I\left[\Delta y_{i t}>\tau\right]$} \\
\hline$\widehat{\tau}$ & $1.2 \%$ & $1.2 \%$ & $1.2 \%$ & $1.2 \%$ & $1.2 \%$ \\
\hline Sup $\mathcal{T}$ & $4.31^{\ddagger}$ & $4.54^{\ddagger}$ & 1.89 & $3.11^{*}$ & $3.11^{*}$ \\
\hline Ave $\mathcal{T}$ & $3.00^{\ddagger}$ & $3.13^{\ddagger}$ & $1.17^{*}$ & $1.88^{\ddagger}$ & $1.98^{\ddagger}$ \\
\hline
\end{tabular}

Notes: The ARDL and DL specifications are given by (8) and (9). The $\operatorname{Sup} \mathcal{T}$ and $A v e \mathcal{T}$ test statistics for the statistical significance of the threshold variable $I\left[\Delta y_{i t}>\tau\right]$ are reported in the Table. ${ }^{*},{ }^{\dagger}$ and ${ }^{\ddagger}$ denote statistical significance at $10 \%, 5 \%$ and $1 \%$ level, respectively.

Table 1 reports the Sup and Ave test statistics for the presence of growth-threshold effects on NPL ratios based on the ARDL and DL specifications, (8) and (9). The Sup and Ave tests results are statistically significant in all cases, irrespective of the choice of the lag order and the estimation procedure (ARDL or DL). Therefore, there appears to be strong support for the presence of growth-threshold effects on NPL ratios in Italy using ARDL and DL specifications at varying lag orders, with the estimates of the threshold being 1.2 percent in all cases.

These non-linear effects could be working through several channels. First, sufficiently-fast 
growth will likely raise the value of collateral and therefore reduce the gap between market and book values of NPLs. Distressed debt investors may have an incentive to wait until they see sustained fast-paced growth before entering the NPLs market. At the same time, as the difference between market and book values of NPLs close, banks will be more willing to write off NPLs. Second, growth exceeding a certain threshold for a period of time may be needed for borrowers in distress to be able to service their debt obligations again, and for the likelihood of further defaults to be reduced. Third, once the economy grows above a certain rate for some time, profitability will be high enough for banks to use retained earnings to build higher capital buffers, further helping them with the write off NPLs. ${ }^{10}$

Against the backdrop of long-standing structural rigidities (including product and service market inefficiencies, wage growth in excess of productivity, high taxation, an inefficient public sector, and lengthy judicial processes), Italy is currently not expected to grow above 1.2 percent over the medium term (see Figure 4). Slow growth has prevailed despite important reform efforts over the past two decades, owing in part to weaknesses in implementation. The potential real GDP growth in Italy exceeded 1.2 percent only before the millennium, and both long-term average real GDP and TFP growth rates are well below those of similar economies. ${ }^{11}$ Therefore, further efforts are needed in three important areas to raise potential growth and help reduce NPL ratios faster: product and service markets; public administration; and wage bargaining reform to align wages with productivity at the firm level and across regions. Moreover, there is a need to actively resolve NPLs as outlined in Section 1. Ensuring a pro-growth mix of spending and tax measures would also help.

\subsection{Estimates of long-run effects}

We now turn our attention to the long-run effects of a persistent pick-up in output growth on NPL ratios, regardless of whether there is a threshold effect. To investigate this, we rely on the ARDL and DL specifications in equations (8) and (9). In a series of papers, Pesaran and Smith (1995), Pesaran (1997), and Pesaran and Shin (1999) show that the traditional ARDL approach can be used for long-run analysis, and that the ARDL methodology is valid regardless of whether the regressors are exogenous, or endogenous, and irrespective of whether the underlying variables are $I(0)$ or $I(1)$. These features of the panel ARDL approach are appealing as reverse causality could be very important in our empirical application. While high NPLs may have an adverse impact on economic growth, low GDP growth could also

\footnotetext{
${ }^{10}$ Although not explicitly testing for threshold effects, Fujii and Kawai (2010) show that in Japan over the period 1997-2007, the outstanding NPL ratio rose when GDP growth was below 1 percent and declined when it exceeded 1 percent, except in one year (2000).

${ }^{11}$ Note that potential output estimates have a high degree of uncertainty.
} 
lead to higher NPLs. We are indeed interested in studying the relationship between output growth and NPL ratios after accounting for these possible feedback effects. We also utilize the DL approach for estimating the long-run relationships for its robustness. Both ARDL and DL specifications allow for a significant degree of cross-region heterogeneity and account for the fact that the effect of a persistent pick-up on growth on NPL ratios could vary across regions (particularly in the short run), depending on region-specific factors such as institutions, geographical location, or cultural heritage.

Table 2: Mean group estimates of the long-run effects of real GDP growth on changes in NPL ratios (1997-2014)

\begin{tabular}{lcrrr}
\hline & \multicolumn{2}{c}{ ARDL } & & \multicolumn{3}{c}{ DL } \\
\cline { 2 - 2 } \cline { 5 - 6 } lags: & $(1,1)$ & $\mathrm{p}=0$ & $\mathrm{p}=1$ & $\mathrm{p}=2$ \\
\hline
\end{tabular}

(a) Regressions with threshold variable $I\left[\Delta y_{i t}>\tau\right]$

$\begin{array}{llllll}\widehat{\theta} & -8.337^{\ddagger} & -8.635^{\ddagger} & -6.944^{\ddagger} & -8.588^{\ddagger} & -9.533^{\ddagger} \\ & (0.5719) & (0.6903) & (0.4643) & (0.5923) & (0.7528)\end{array}$

(b) Regressions without threshold variables

$\begin{array}{llllll}\widehat{\theta} & -6.472^{\ddagger} & -6.522^{\ddagger} & -6.676^{\ddagger} & -7.016^{\ddagger} & -7.541^{\ddagger} \\ & (0.5616) & (0.7994) & (0.5811) & (0.7304) & (0.5139) \\ & & & & & \end{array}$

Notes: The ARDL and DL specifications are given by (8) and (9). Standard errors are given in parentheses. Statistical significance is denoted by ${ }^{*},{ }^{\dagger}$ and ${ }^{\ddagger}$, at $10 \%, 5 \%$ and $1 \%$ level, respectively.

The least squares estimates obtained from the panel ARDL and DL specifications are reported in Table 2. Panel (a) reports the results for models with threshold variables. Panels (b) shows the results when the threshold variables are excluded. Each panel gives the Mean Group (MG) estimates of the long-run effects of real GDP growth, $\Delta y_{i t}$, on changes in NPL ratios. As shown in Pesaran and Smith (1995), the MG estimates are consistent under fairly general conditions so long as the errors are cross-sectionally independent.

The results across all specifications suggest an inverse relationship between GDP growth and changes in NPL ratios. Specifically, Table 2 shows that the coefficients of real GDP growth, $\widehat{\theta}$, are negative and statistically significant at the 1 percent level, with their values ranging from -6.5 to -9.5 across various estimation techniques (ARDL and DL), and lag orders. In other words, a one percentage point faster growth than the baseline, if it persists, would reduce the ratio of NPLs by about 6.5 to 9.5 percent per year (i.e., halving the NPL stock in $3-6$ years). 


\subsection{Robustness to inflation dynamics}

To check the robustness of our analysis to inflation dynamics, we ran the model with nominal GDP growth and got a "nominal GDP growth" threshold estimate of about 3 percent (Table 3). Note that GDP deflator in Italy grew on average by about 2 percent over 1997-2014. Considering that inflation in Italy is projected to remain significantly below the European Central Bank's target of 2 percent, a decisive reduction in NPL overhang relies on improving the underlying real growth dynamics (i.e. real GDP growth above 1.2 percent).

Table 3: Tests of nominal GDP growth-threshold effects on changes in NPL ratios

\begin{tabular}{|c|c|c|c|c|c|}
\hline \multirow[b]{2}{*}{ lags: } & \multicolumn{2}{|c|}{ ARDL } & \multicolumn{3}{|c|}{ DL } \\
\hline & $(1,1)$ & $(2,2)$ & $\mathrm{p}=0$ & $\mathrm{p}=1$ & $\mathrm{p}=2$ \\
\hline \multicolumn{6}{|c|}{ Regressions with threshold variable $I\left[\Delta y_{i t}^{\text {nominal }}>\tau\right]$} \\
\hline$\widehat{\tau}$ & $3.0 \%$ & $3.0 \%$ & $3.0 \%$ & $3.0 \%$ & $3.0 \%$ \\
\hline $\operatorname{Sup} \mathcal{T}$ & $4.78^{\ddagger}$ & $4.53^{\ddagger}$ & $3.59^{\ddagger}$ & $3.04^{*}$ & 2.84 \\
\hline Ave $\mathcal{T}$ & $3.01^{\ddagger}$ & $2.93^{\ddagger}$ & $1.76^{\ddagger}$ & $1.57^{\ddagger}$ & $1.26^{*}$ \\
\hline
\end{tabular}

Notes: The ARDL and DL specifications are given by (8) and (9). The $\operatorname{Sup} \mathcal{T}$ and Ave $\mathcal{T}$ test statistics for the statistical significance of the threshold variable $I\left[\Delta y_{i t}^{\text {nominal }}>\tau\right]$ are reported in the Table. ${ }^{*},{ }^{\dagger}$ and ${ }^{\ddagger}$ denote statistical significance at $10 \%, 5 \%$ and $1 \%$ level, respectively.

\section{Concluding remarks}

We provided a formal statistical analysis of growth threshold effects on NPL ratios in a panel of 17 Italian regions over the period 1997-2014. To deal with different types of econometric issues and ensure robustness, we conducted the NPL-growth exercise based on two estimation methods (ARDL and DL). Our results suggest that for Italy there is a growth-threshold effect of about 1.2 percent in the relationship between real GDP growth and NPL ratios. That is, persistent real GDP growth above 1.2 percent for a number of years is needed to reduce NPL ratios significantly over the medium term. However, achieving average growth rates above 1.2 percent requires tackling long-standing structural rigidities, lowering Italy's high levels of public debt, and ensuring a pro-growth mix of spending and tax measures. There is also an urgent need for additional financial sector measures to clean up bank balance sheets. While the authorities have already introduced a number of measures to deal with the NPL problem, additional measures could help bring down NPL ratios faster, including by more 
intensive use of out-of-court debt restructuring mechanisms; and strengthened supervision to facilitate decisive progress in reducing NPLs, among others.

\section{References}

Balgova, M., M. Nies, and A. Plekhanov (2016). The Economic Impact of Reducing NonPerforming Loans. EBRD Working Paper Number 193.

Beck, R., P. Jakubik, and A. Piloiu (2013). Non-Performing Loans What Matters in Addition to the Economic Cycle? ECB Working Paper Series No 1515.

Bofondi, M. and T. Ropele (2011). Macroeconomic Determinants of Bad Loans: Evidence from Italian Banks. Bank of Italy Occasional Papers No 89.

Caballero, R. J., T. Hoshi, and A. K. Kashyap (2008, December). Zombie Lending and Depressed Restructuring in Japan. American Economic Review 98(5), 1943-77.

Chudik, A., K. Mohaddes, M. H. Pesaran, and M. Raissi (2016). Long-Run Effects in Large Heterogeneous Panel Data Models with Cross-Sectionally Correlated Errors. In R. C. Hill, G. Gonzalez-Rivera, and T.-H. Lee (Eds.), Advances in Econometrics (Volume 36): Essays in Honor of Aman Ullah, Chapter 4, pp. 85-135. Emerald Publishing.

Chudik, A., K. Mohaddes, M. H. Pesaran, and M. Raissi (2017). Is There a Debt-threshold Effect on Output Growth? Review of Economics and Statistics 99(1), 135-150.

Dörr, S., M. Raissi, and A. Weber (2017). Credit-Supply Shocks and Firm Productivity in Italy. IMF Working Paper, forthcoming.

Espinoza, R. and A. Prasad (2010). Nonperforming Loans in the GCC Banking Systems and their Macroeconomic Effects. IMF Working Paper WP/10/224.

Filosa, R. (2007). Stress Testing of the Stability of the Italian Banking System: A VAR Approach.

Fujii, M. and M. Kawai (2010). Lessons from Japan's Banking Crisis, 1991-2005. Asian Development Bank Institute Working Paper Series No. 222.

Garrido, J., E. Kopp, and A. Weber (2016). Cleaning-up Bank Balance Sheets: Economic, Legal, and Supervisory Measures for Italy. IMF Working Paper WP/16/135. 
Glen, J. and C. Mondragón-Vélez (2011). Business cycle effects on commercial bank loan portfolio performance in developing economies. Review of Development Finance 1(2), 150165.

International Monetary Fund, . (2016). IMF Country Report No. 16/222.

Jobst, A. and A. Weber (2016). Profitability and Balance Sheet Repair of Italian Banks. In Italy: Selected Issues, IMF Country Report No. 16/223. International Monetary Fund, Washington.

Klein, N. (2013). Non-Performing Loans in CESEE : Determinants and Impact on Macroeconomic Performance. IMF Working Paper WP/13/72.

Mohaddes, K. and M. Raissi (2016). Does Inflation Slow Long-Run Growth in India? In R. Anand and P. Cashin (Eds.), Taming Indian Inflation, pp. 115-129. International Monetary Fund, Washington D.C.

Nkusu, M. (2011). Nonperforming Loans and Macrofinancial Vulnerabilities in Advanced Economies. IMF Working Paper 11/161.

Notarpietro, A. and L. Rodano (2016). The Evolution of Bad Debt in Italy During the Global Financial Crisis and the Sovereign Debt Crisis: A Counterfactual Analysis. Bank of Italy Occasional Papers No 350.

Peek, J. and E. S. Rosengren (2005). Unnatural Selection: Perverse Incentives and the Misallocation of Credit in Japan. American Economic Review 95(4), 1144-1166.

Pesaran, M. H. (1997). The Role of Economic Theory in Modelling the Long Run. Economic Journal 10\%, 178-191.

Pesaran, M. H. and Y. Shin (1999). An Autoregressive Distributed Lag Modelling Approach to Cointegration Analysis. In S. Strom (Ed.), Econometrics and Economic Theory in 20th Century: The Ragnar Frisch Centennial Symposium, Chapter 11, pp. 371-413. Cambridge: Cambridge University Press.

Pesaran, M. H. and R. Smith (1995). Estimating Long-run Relationships from Dynamic Heterogeneous Panels. Journal of Econometrics 68(1), 79-113.

Quagliariello, M. (2007). Banks' Riskiness Over the Business Cycle: A Panel Analysis on Italian Intermediaries. Applied Financial Economics 17(2), 119-138. 